\title{
The Real Drivers of Climate Change?
}

\author{
David Finlay: david@theethicaldairy.co.uk
}

( the paper is a non-peer reviewed preprint submitted to EarthArXiv.)

\section{Background}

The evidence that we are heading for irreversible, human caused climate change with potentially catastrophic outcomes is now overwhelming. Despite all the rhetoric about addressing the causes of this crisis, globally to date little has been achieved. Perhaps this is now about to change.

In the run-up to the COP 26 global climate summit in Glasgow this November, governments and corporations across the world are rushing to demonstrate that they have a road map to, so called, 'net zero'. Net zero is where greenhouse gas emissions from somewhere are balanced by carbon that is locked up/sequestered in some way, often elsewhere. A popular method of achieving net zero is to buy carbon credits from those who are certified sequesterers of carbon through trading platforms like the UK and EU's emissions trading schemes (ETS). That the price of these carbon credits has shot up from the teens of euros where it had languished for many years to around 60 euros per tonne in recent months is an indication that things are moving.

All this activity centres around the strategy (Kyoto $1997^{1}$ ) of bringing climate change under control through reducing our net emissions of greenhouse gases to zero by 2050. But there's a potential problem.

Now that governments, corporations and most individuals have got their heads around the idea of cutting carbon emissions, it seems that a kind of 'group think' mentality ${ }^{2}$ has set in. The sheer momentum that has been built around the evidence of the hundreds of scientists working in their respective climate fields has allowed us to ignore a growing science indicating that this strategy to address the threat of climate change may be fundamentally flawed.

This paper does not in any way question the veracity of the research of these scientists, but it does bring into question the logic behind the direction of travel at a strategic level, once the results are viewed from an entirely different perspective. 


\section{Straws in the Wind}

An early indicator that all was not as it seemed came from work by palaeontologist - Professor WF Ruddiman ${ }^{3}$. His study of the causes of periods of global glaciation suggested that we should have been entering a glaciation period 5000 years ago but didn't.

GRAPH. Demonstrating the calculated deviation between the natural global temperature (without human intervention) trend and the actual.

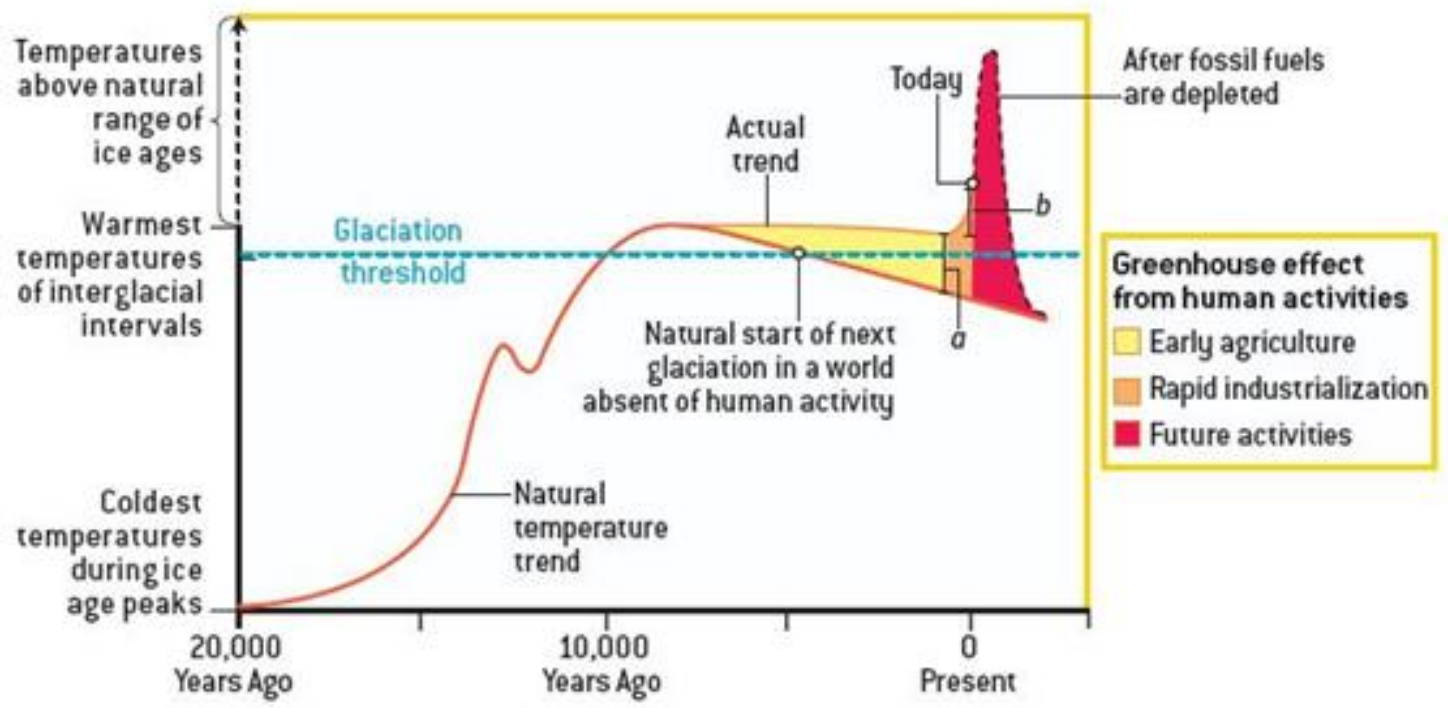

He surmised that humans, through their accumulating ecological impact over thousands of years (deforestation, mass slaughter of wild herbivores, wildfires - deliberate or consequential - and early agriculture), were already causing global warming. By the beginning of the industrial revolution, he reckoned, the earth was experiencing one degree of human-caused global warming ('a' on the graph). That is, the earth was one degree warmer than it would have been in the absence of humans. This, at a time when global atmospheric concentrations of $\mathrm{CO} 2$ and methane were rising but still within their long-term 'normal' levels 4,5 , suggested to some that another force might be having a significant influence on the global climate. 


\section{Drivers of Climate Change}

An important piece of research, published in 2018, studied the effects on climate arising from changes in land use (primary forest, open woodland, grassland, arable and shrubland) at a global level ${ }^{6}$. The quality of satellite data now available allowed these researchers to study how incoming solar energy was dissipated from the earth's surface (reflected, radiated, evaporated, etc.) under these different land use scenarios. They then calculated the change in net energy that was emitted by the earth's surface back into the atmosphere as a direct result of these changes in land use.

It has long been known that as a surface heats up it emits more energy. It has also been known that, as the vegetation covering the land changes from primary forest through various stages of degradation to desert, so the surface temperature increases. However, this has never before been studied in detail and with real-time data at a global level. Incoming energy from the sun is primarily in the form of short wavelength energy that, largely, passes through the atmosphere unhindered by the greenhouse gases. In contrast, the significance of the energy radiated back from the earth's surface is that it is in the form of longwave energy which is the type of energy that is trapped by greenhouse gasses. Their findings were pretty startling.

They found that while there was a significant increase in reflected short wavelength heat there was also substantial extra longwave energy radiated into our atmosphere to be trapped by greenhouse gases, as a result of land use changes over the 15-year study period. This amounted to around 55 million, trillion Joules (known as exajoules $-x 10$ to the $18^{\text {th }}$ power) annually. Even at a global level, that is significant.

Over that 15 -year study period, around $80 \%$ of the extra longwave energy radiated into the atmosphere from land use change came from the transition of primary, equatorial forest (EBF) to cropland (CRO) to feed the industrial livestock sector.

Looking at the table below, the top bar shows the total annual cumulated energy change over the 15 -year study period. The reduction in terrestrial heat emissions as sensible, ground and latent (evaporation) heat emissions (to the left of the table) is balanced by gains of heat emitted as short wavelength reflected heat and long wavelength radiated heat (to the right of the table). Of the total 120 exajoule gain, around 55 exajoules is longwave heat radiation. This is additional heat radiated from the earth's surface adding to the total heat trapped by the greenhouse gases and undoubtedly contributing to global warming. Not only that, but there is an equivalent loss of the cooling effect of evapotranspiration (latent heat, to the left of the table) and huge disruption to the water cycle from loss of forest and vegetative ground cover.

But that is just the tip of the iceberg. 
These figures don't include urban and industrial sprawl over the past century which amounts to a similar area to that of the study, but is an even more extreme change of land use. For example an Australian study found that surface temperature differences between urban forest (over $30 \%$ canopy cover) and urban heat islands could reach 130deg.C ${ }^{12}$. However, these are all eclipsed by the loss of agricultural land to desert which at $12 \mathrm{Mha}$ per year ${ }^{7}$ is 6 times the area of deforestation and which again is a more extreme form of land use change than even forest to crop. Finally, there is the global loss of ice-cover, exposing darker underlying surfaces with much lower reflective properties and higher radiative ones. While the radiative differences might be relatively small, these areas are, once again, substantial.

TABLE. Cumulated changes in energy for each component of the surface energy balance resulting from recent major vegetation transitions 2000-2015.

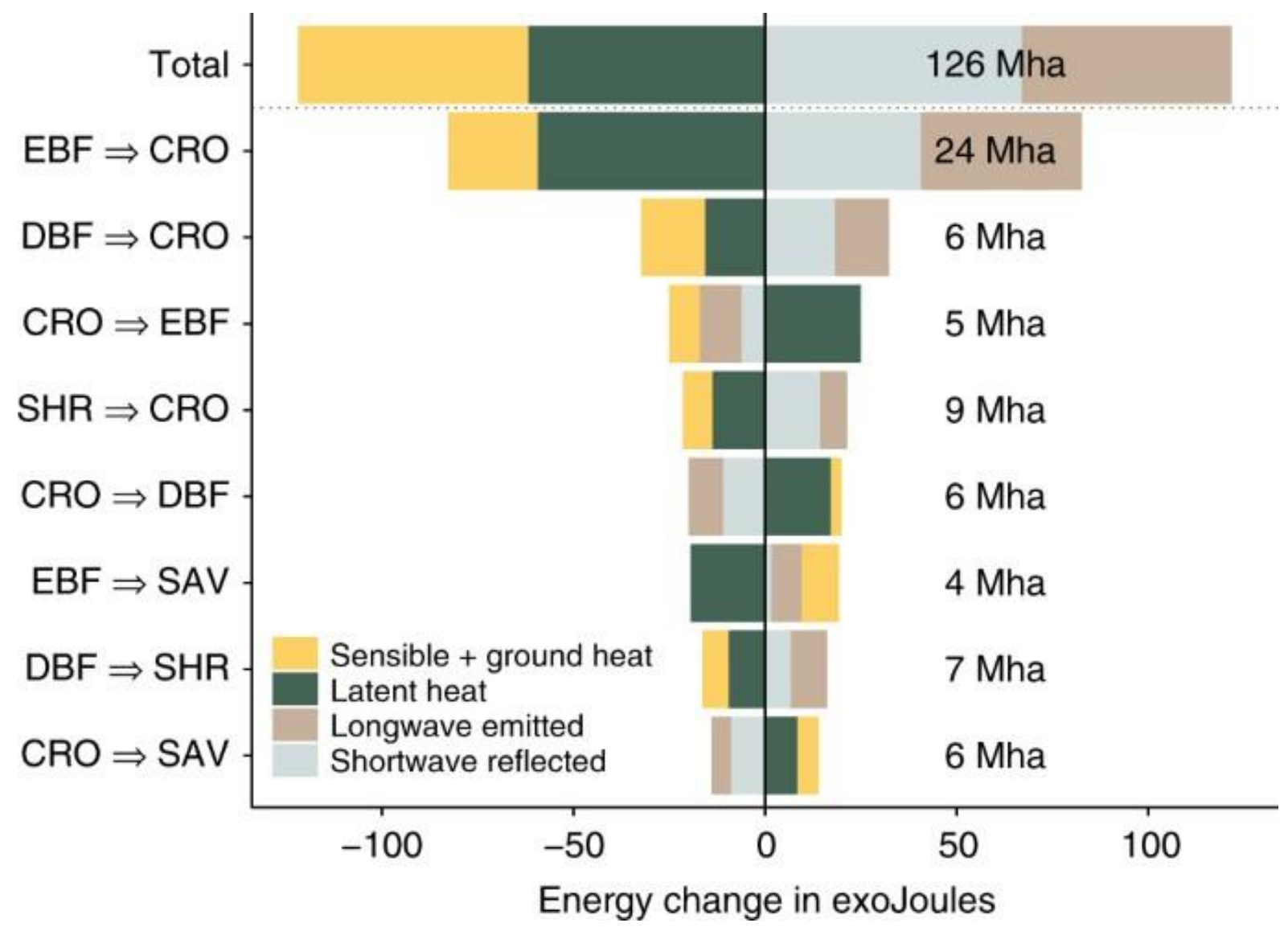

Transitions are sorted according to decreasing absolute change in the surface energy balance. The changed area per transition, calculated based on the ESA CCI land cover maps of 2015 and 2000, are reported in mega-hectares on the right of the bars. The transitions shown involve the following vegetation classes: evergreen broadleaf forests (EBF), deciduous broadleaf forests (DBF), savannas (SAV), shrublands (SHR) and croplands (CRO) 
It doesn't even end there. Let's do some simple maths. FAO data ${ }^{8}$ tell us that in the past 400 years the amount of land used for agricultural production has mushroomed from 900 Million ha to almost 5,000Mha. We can assume that most of that has come from previously forested land. From the table above we can see that a total of around 40Mha of forest were converted to crop and grassland over the period of the study, generating an extra 76 exajoules - EJ (or 76 followed by eighteen zeros) of longwave energy radiated annually from the earth's surface into our atmosphere. On that basis, the conversion of 4,000Mha from forest to agriculture might reasonably be expected to generate 7,600EJ of extra, radiated longwave energy. We convert this to Watts by dividing by the number of seconds in a year ( 31.5 million) to give us 250 trillion Watts. Divide this again by the surface area of the world (510sq. terametres) and we get $0.5 \mathrm{~W} / \mathrm{m} 2$. This is almost half the imbalance of energy entering and leaving our atmosphere ${ }^{9}$ that is causing global warming. It doesn't include desertification, built areas and loss of ice cover nor the corresponding loss of evaporative cooling from the loss of vegetative cover.

Having ploughed through the latest IPCC climate change report and various other reports from climate authorities, I can find no reference to the contribution that increases in terrestrial radiation might make to climate change and yet that contribution appears to be very significant. But the problem doesn't end there either.

\section{The Greenhouse Gas You Never Heard Of}

There's a greenhouse gas in our atmosphere that is rarely mentioned. Each molecule is a more effective blocker of longwave heat radiated from the earth than $\mathrm{CO} 2{ }^{10}$. It occurs in our atmosphere about 60 times more frequently than $\mathrm{CO} 2$ and 14,000 times more than methane. It's called water vapour and it has a 95\% influence over the atmosphere's heat changes ${ }^{11}$.

It's dismissed as a greenhouse gas by climate scientists because of its short life cycle as a gas in the atmosphere. The effectiveness of a greenhouse gas is measured by its Global Warming Potential (GWP). This is the product of each molecule's ability to block radiated energy and how long it remains in the atmosphere after it is emitted. While this is reasonable for a gas that is emitted by our activities, it seems inappropriate to use this method to determine the GWP of a gas whose presence in the atmosphere is overwhelmingly controlled by natural processes.

Water vapour is extremely variable - from $0.01 \%$ to $5 \%$ of atmospheric gases - depending on temperature, location, and humidity. It is difficult to measure accurately and finally we have little or no control over it. It is considered more of a feed-back response to the climate effects of the greenhouse gases that we do have some control over, as its frequency of occurrence rises and falls with global temperature. However, these arguments for dismissing it are only valid if our sole means of climate control is through the regulation of our greenhouse gas emissions.

When we take into consideration the effects of changing land use (over which we do have considerable control), it turns this argument on its head. From a perspective of long-wave 
radiation increase by human-caused terrestrial land-use change we must consider the contribution of each greenhouse gas to the overall atmospheric 'insulating blanket' effect. This is based on each greenhouse gas's frequency of occurrence in our atmosphere and its effectiveness as an absorber of longwave heat radiation. Thus, the role of water vapour as a greenhouse gas in its own right becomes critical. From the perspective of increases in longwave heat radiation as a result of land use change, water vapour totally dominates the narrative.

\section{Discussion}

From the evidence above it appears that the widely accepted approach to addressing global warming through reducing greenhouse gas emissions alone will be doomed to failure. Exchanging our fossil fuel driven chainsaws, excavators and agricultural cultivating equipment for electric or hydrogen driven ones to allow our continued destruction of the global ecology is utter folly. As perhaps most of us have felt intuitively, these ecological crises are all connected. Not only are they connected, THEY ARE ONE AND THE SAME. It is the destruction of that ecology and resulting increase in terrestrial, radiative heat emissions as well as the loss of evaporative cooling that is the primary driver of climate change.

The rise in atmospheric greenhouse gases in association with global warming is more a symptom of our destructive impact on our planet than the primary causation of climate change.

At a purely intuitive level it certainly makes more sense (at least to me) that a phenomenon as massive as global warming is more likely to result from substantial change, the like of which we are witnessing from our cumulated destruction of the global ecology, than it would from a rise of 1 or 2 parts of a greenhouse gas per 10,000 parts of gases in our atmosphere.

It may not sound like it, but in fact this is good news. We might still have a short window of opportunity to bring global warming under some sort of control. Our efforts to reduce our greenhouse gas emissions, to date, have been a miserable failure and, with what some see as the 'smoke-and-mirrors' emissions accounting methodologies, the prospects for any kind of success are both remote and futile.

Controlling global warming through regenerative practices is something we can all wholeheartedly support and, indeed, participate in. Halt deforestation, stop cereal/soya-based intensive livestock farming, re-build forests/woodlands, plant cover crops on arable land, encourage agroecological and agroforestry farming systems, green urban areas and so on. It reverses global warming, re-builds biodiversity, creates meaningful jobs, reduces pollution and antibiotic resistance and, most importantly, is real, nature-based (thus intrinsically safer) and achievable. 


\section{References}

1. https://www.pnas.org/content/98/9/4850

2. https://www.psychologytoday.com/gb/basics/groupthink

3. https://physics.ucf.edu/ britt/Climate/Reading5Did\%20humans\%20alter\%20global\%20climate.pdf

4. https://commons.wikimedia.org/wiki/File:Ghgs-epcia-holocene-CO2-en.svg

5. https://www.methanelevels.org

6. https://www.nature.com/articles/s41467-017-02810-8\#Sec2

7. https://www.unccd.int/actions/united-nations-decade-deserts-2010-2020-and-fight-againstdesertification

8. https://ourworldindata.org/land-use

9. https://www.nasa.gov/sites/default/files/thumbnails/image/figure 1 v2.gif

10. https://physicstoday.scitation.org/doi/10.1063/PT.3.2009\#comments

11. https://latimesblogs.latimes.com/greenspace/2011/11/greenhouse-gases-water-vapor-and-you.html

12. https://www.cmtedd.act.gov.au/open government/inform/act government media releases Lrattenbury/2018/urban-heat-islands-the-heat-is-on 